\title{
Ciência da Computação e Engenharia de Software: semelhanças e diferenças a partir da realidade dos egressos
}

\author{
Aline Vieira de Mello ${ }^{1}$, Alice Fonseca Finger ${ }^{1}$, Andréa Sabedra Bordin ${ }^{1}$ \\ ${ }^{1}$ Universidade Federal do Pampa (UNIPAMPA) \\ Av. Tiaraju, 810 - 97.546-550 - Alegrete - RS - Brazil \\ \{alinemello, alicefinger, andreabordin\}@unipampa.edu.br
}

\begin{abstract}
In Brazil, the National Curriculum Guidelines for undergraduate programs in Computing establish what is expected of graduates of each program in the area. Specifically concerning the undergraduate programs in Computer Science (CS) and Software Engineering (SE) are instituted some differences, but also several similarities, which can result in graduates with very similar profiles. Considering this scenario, the present work aims to show the profiles of CS and SE from the graduates' reality, identifying the similarities and differences. The results obtained show that there are differences between the profiles about professional performance, which cannot be stated about academic education.
\end{abstract}

\begin{abstract}
Resumo. No Brasil, as Diretrizes Curriculares Nacionais dos cursos de graduação de Computação estabelecem o que é esperado dos egressos de cada curso da área. Especificamente em relação aos cursos de Ciência da Computação (CC) e Engenharia de Software (ES) são instituídas algumas diferenças mas também várias semelhanças, o que pode resultar em egressos com perfis muito parecidos. Em vista disso, o presente trabalho tem como objetivo apresentar os perfis de CC e ES a partir da realidade dos egressos, identificando as semelhanças e diferenças. Os resultados obtidos mostram que existem diferenças entre os perfis em relação à atuação profissional, o que não pode ser afirmado em relação à formação acadêmica.
\end{abstract}

\section{Introdução}

As Diretrizes Curriculares Nacionais (DCN) dos cursos de graduação da área de Computação [Ministério da Educação 2016], além de apresentarem o perfil geral dos cursos, trazem o perfil específico e estabelecem as habilidades e competências esperadas para cada curso da área. Ao analisar as habilidades e competências do bacharelado em Ciência da Computação (CC) e do bacharelado em Engenharia de Software (ES), notam-se características que diferenciam os dois perfis. Entretanto, em relação aos perfis específicos dos dois cursos, percebe-se que existem algumas diferenças, mas também várias semelhanças.

De acordo com o portal e-MEC [1] existem hoje 25 instituições de ensino superior que oferecem os cursos de graduação em CC e ES na modalidade presencial, sendo 15 instituições privadas e 10 públicas. Segundo Hazzan [Hazzan 2007], muitas vezes cientistas da computação e engenheiros de software recebem a mesma educação, a qual é, na

\footnotetext{
${ }^{1}$ https://emec.mec.gov.br/
} 
maioria dos casos, fornecida pelo mesmo corpo docente. Isso tende a resultar em egressos com perfis semelhantes. Assim, é importante identificar se na prática essa realidade se confirma, tanto na perspectiva da pós-graduação quanto do mercado de trabalho.

Uma busca na literatura não retornou trabalhos que abordem as diferenças entre os cursos CC e ES através da análise do perfil dos egressos. Alguns estudos visam estabelecer as diferenças entre os dois cursos por meio da análise do currículo dos cursos [Parnas 1999, Meziane and Vadera 2004, Rasool and Tahir 2014]. Outros trabalhos abordam a análise de um dos perfis de cursos da área de Computação, como [Garcia et al. 2018] que traça o perfil de egressos de CC da UFSM; ou realizam a comparação entre dois perfis, como [da Silva Figueiredo et al. 2018] que compara os perfis de egressos de CC e Sistemas de Informação da UFMT.

Neste contexto, o objetivo deste trabalho é identificar semelhanças e diferenças entre os perfis dos cursos CC e ES a partir da realidade dos egressos. Para isso foi realizado um survey com os egressos dos dois cursos da Universidade Federal do Pampa (UNIPAMPA), a qual permitiu uma análise tanto da formação acadêmica quanto da atuação profissional. Os resultados deste estudo, obtidos a partir de uma amostra significativa de respondentes, podem contribuir em uma melhor adequação dos currículos, principalmente em instituições que oferecem os dois cursos.

O restante deste documento está organizado como segue: na Seção 2, a metodologia adotada é descrita; os resultados são apresentados na Seção 3 e discutidos na Seção 4; e, por fim, na Seção 5 são apresentadas as considerações finais.

\section{Metodologia}

A UNIPAMPA oferta o curso CC desde 2006 [UNIPAMPA 2009] e o curso ES desde de 2010 [UNIPAMPA 2010]. Os dois cursos possuem o mesmo corpo docente, embora alguns docentes atuem majoritariamente em um dos cursos. Dentre as diferenças a serem pontuadas, destaca-se que o curso ES adota a metodologia Aprendizagem Baseada em Problemas (ABP) de forma transversal no currículo e possui estágio obrigatório.

No período de fevereiro a abril de 2020 foi realizado um survey com egressos dos cursos até o primeiro semestre de 2019. O instrumento utilizado para a coleta de dados foi um questionário elaborado a partir de várias referências bibliográficas e documentos técnicos, dentre eles [da Silva Figueiredo et al. 2018] e [Brasscom 2017]. O questionário ${ }^{2}$ contém entre 70 e 210 questões (dependendo das respostas fornecidas) divididas em três dimensões: sociodemográfica, formação acadêmica e atuação profissional.

A dimensão sociodemográfica contém as questões relacionadas a sexo; data de nascimento; cidade, estado e país de residência; dentre outras. A dimensão formação acadêmica contempla várias questões relacionadas à graduação e pós-graduação. Neste trabalho, no que tange a graduação, somente as questões referentes ao ano de ingresso e conclusão do curso foram utilizadas. Em relação à pós-graduação, as questões de interesse do trabalho foram: tipo, nome e instituição de ensino da pós-graduação e área de pesquisa. A dimensão atuação profissional contém questões sobre a inserção no mercado de trabalho; o número de instituições trabalhadas, e para cada instituição: seu nome, cidade, estado, país, cargo ocupado, faixa de remuneração, dentre outras.

\footnotetext{
${ }^{2}$ Disponível em: http://bit.ly/egressosCCESUNIPAMPA
} 


\section{Resultados}

O questionário foi enviado para 155 egressos, 103 de CC e 55 de ES. Desses, 98 responderam completamente, sendo 61 egressos de CC (59,2\%) e 37 egressos de ES (67,2\%), o que significa que o survey possui um nível de confiança de 95,0\% com erro amostral de $6,0 \%$. Os resultados são apresentados de acordo com as dimensões de dados coletados.

\subsection{Dimensão Sociodemográfica}

O número de respondentes agrupados por curso e ano de conclusão da graduação é exibido na Figura 1. Observa-se que foram obtidas respostas de egressos de todos os anos, desde as primeiras turmas de egressos de CC (2010) e de ES (2013). Adicionalmente, a maioria dos respondentes, independentemente do curso, se graduou antes de 2017, ou seja, possuem mais de 3 anos de formados.

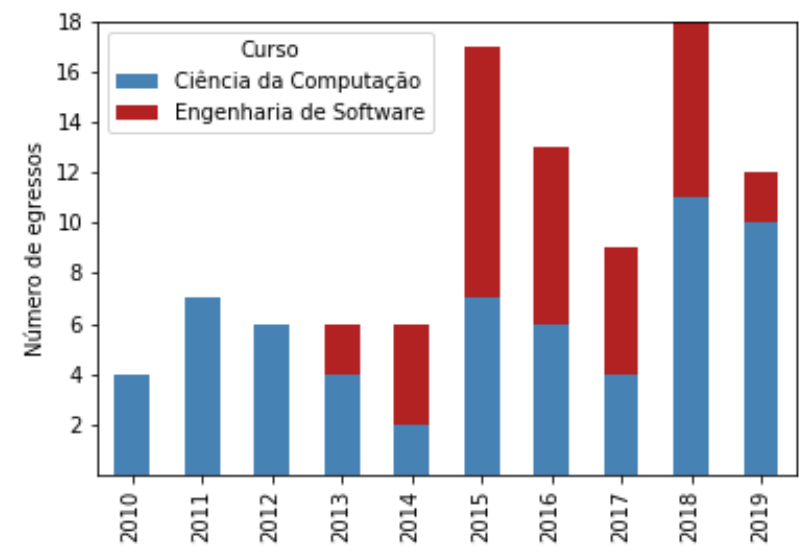

Figura 1. Egressos por curso e ano de conclusão

A Tabela 1 exibe o número de egressos por sexo, faixa etária, estado civil e número de filhos. Os respondentes, independente do curso, são majoritariamente do sexo masculino, possuem menos de 30 anos, são solteiros e não possuem filhos. Destaca-se que as mulheres representam somente 18,0\% dos respondentes de CC e 13,6\% de ES.

Tabela 1. Número de egressos por sexo, faixa etária, estado civil e número de filhos

\begin{tabular}{|c|c|c|c|c|c|c|c|c|c|c|c|}
\hline & \multicolumn{2}{|c|}{ Sexo } & \multicolumn{3}{|c|}{ Faixa Etária } & \multicolumn{3}{|c|}{ Estado Civil } & \multicolumn{3}{|c|}{ Filhos } \\
\hline & $\mathrm{M}$ & $\mathrm{F}$ & {$[20,30]$} & ] $30,40]$ & ] $40,50]$ & Solt. & Casado & Divorc. & 0 & 1 & 2 \\
\hline $\mathrm{CC}$ & 50 & 11 & 41 & 19 & 1 & 41 & 17 & 3 & 56 & 3 & 2 \\
\hline ES & 32 & 5 & 26 & 11 & 0 & 31 & 6 & 0 & 30 & 4 & 3 \\
\hline
\end{tabular}

Atualmente, a maioria dos egressos de CC (62,3\%) e ES (70,3\%) reside no estado do Rio Grande do Sul (RS), seguido pelo estado de Santa Catarina. Ao analisar de forma mais detalhada, destaca-se que a maior parte dos egressos dos dois cursos residem em Alegrete/RS, cidade onde os cursos são ofertados, e Porto Alegre/RS.

\subsection{Formação Acadêmica - Pós-Graduação}

A Tabela 2 mostra o número de egressos de CC e ES que realizaram ou realizam cursos por tipo de pós-graduação, onde E indica aqueles que fizeram somente Especialização ou 
MBA, M aqueles que cursaram apenas Mestrado, E-M os que fizeram Especialização e Mestrado, M-D os que fizeram Mestrado e Doutorado, E-M-D aqueles que fizeram os três tipos de curso e, por fim, aqueles que não cursaram nenhuma pós-graduação.

Tabela 2. Número de egressos por tipo de pós-graduação

\begin{tabular}{l|c|c}
\hline Pós-Graduação & CC & ES \\
\hline E & 2 & 6 \\
M & 21 & 17 \\
E-M & 4 & 0 \\
D & 1 & 0 \\
M-D & 9 & 4 \\
E-M-D & 2 & 0 \\
Nenhuma & 22 & 10 \\
\hline
\end{tabular}

Dentre os que fizeram especialização ou MBA (8 de CC e 6 de ES), as áreas escolhidas pelos egressos de CC foram: Docência do Ensino Superior (3), Computação Forense, Engenharia de Sistemas, Big Data, Redes de Computadores, e Mídias para a Educação. Já os egressos de ES escolheram: Gestão de Projetos (2), Gestão da Qualidade, Aplicações para Web, Inovação e Design Estratégico, e Business Intelligence.

Em relação ao mestrado, as instituições escolhidas pelos egressos são apresentadas na Figura 2. Nota-se que um grande número de egressos de CC e ES optou por realizar o mestrado na mesma instituição de graduação (UNIPAMPA), seguido por outras instituições localizadas no RS. Dos egressos de CC, 89\% escolheram como área de pesquisa CC e $11 \%$ escolheram a área de ES. Já entre os egressos de ES, $62 \%$ optaram pela área de ES e $38 \%$ pela área de CC.

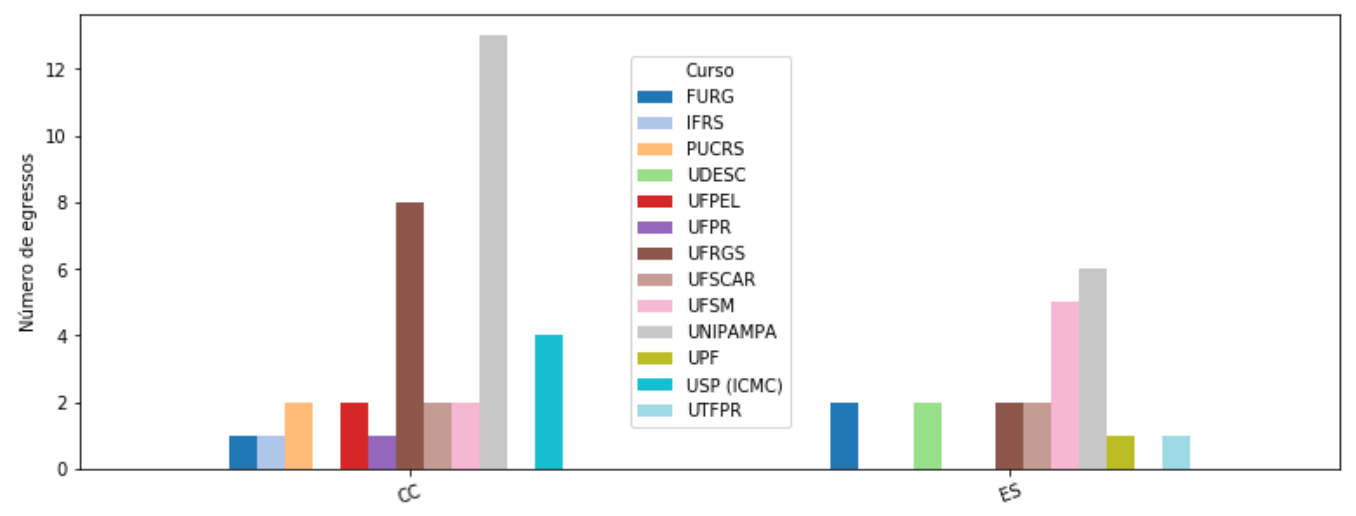

Figura 2. Número de egressos por instituição do programa de mestrado

A Figura 3 exibe as áreas de pesquisa dos egressos no mestrado. As três áreas mais procuradas pelos egressos de CC foram: Sistemas Inteligentes (SI) (9), Computação Paralela e Distribuída (CPD) (6), e Redes e Comunicações (RC) (5). Entre os egressos de ES, as áreas mais pesquisadas foram: Qualidade de Software (QS) (3), Desenvolvimento de Software (DS) (2) e Manutenção de Software (MS) (2).

Em relação ao doutorado, a maioria dos egressos de CC (8) optaram por instituições localizadas no RS (UFRGS (4), PUCRS (3) e UFPEL); 2 por instituições 


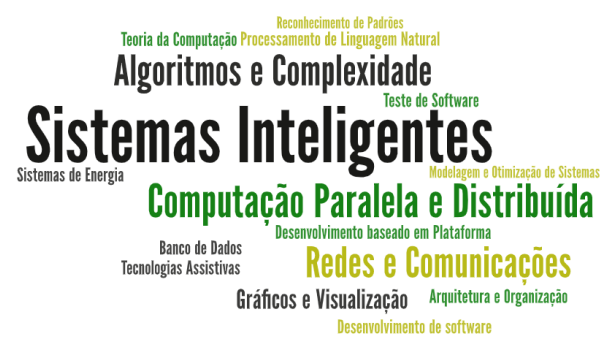

(a) $\mathrm{CC}$

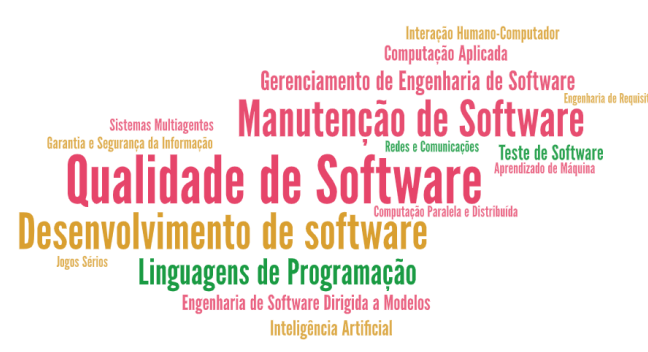

(b) ES

Figura 3. Áreas de pesquisa do mestrado

localizadas em outros estados brasileiros (UFG e USP-ICMC); e outros 2 por instituições no exterior (Universidade de Lisboa e Monash University). Já os 4 egressos de ES escolheram as seguintes instituições: UFPEL, UFF, UFSC e USP-ICMC. Com exceção dos egressos que estão no exterior, os quais entraram em programas de Tecnologia da Informação e Engenharia Eletrônica e de Computadores, todos os outros, independentemente do curso, realizam doutorado em programas de pós-graduação em CC.

No doutorado, as áreas pesquisadas pelos egressos de CC foram: Sistemas Inteligentes (4); Computação Paralela e Distribuída (4); Redes e Comunicações; Garantia e Segurança da Informação; Engenharia de Software; e Interação Humano-Computador. Já entre os egressos de ES, as áreas foram: Sistemas Inteligentes (2); Computação Paralela e Distribuída; e Garantia e Segurança da Informação.

\subsection{Atuação Profissional}

Dos respondentes, 81 tiveram alguma experiência no mercado de trabalho, sendo 46 de CC e 35 de ES, o que corresponde a 75,4\% dos respondentes de CC e 94,6\% dos respondentes de ES. Dos 15 egressos de CC que ainda não tiveram experiência no mercado de trabalho, 8 estão realizando mestrado e 4 doutorado. Já dos 2 egressos de ES que nunca atuaram no mercado de trabalho, um está realizando mestrado e o outro doutorado.

Sobre o nível de dificuldade para a inserção no mercado de trabalho, os egressos de ES (70,3\%) consideraram mais fácil do que os egressos de CC (59,0\%). Conforme a Figura 4 mostra, 50\% dos egressos de CC ingressaram no mercado de trabalho em até 6 meses após a graduação, enquanto 62,9\% dos egressos de ES se inseriram no mercado no mesmo período de tempo.

Dos egressos que já atuaram no mercado de trabalho (81), os egressos de CC (46) atuaram em até 6 instituições e os egressos de ES (35) em até 5 instituições. Contudo, em média, os egressos de ambos os cursos atuaram em 2 instituições. Ao todo, os egressos de CC atuaram em 89 instituições, sendo 83 instituições no Brasil e 6 no exterior (Estados Unidos (2), Polônia (2), Israel e Portugal). Já os egressos de ES atuaram em 68 instituições, todas brasileiras.

As atuações dos egressos foram categorizadas como segue: (1) TI - atuação em instituição do ramo de TI; (2) TI in House - atuação em um cargo da área de TI em instituição de diferentes ramos; (3) Educacional - atuação em um cargo relacionado à área de formação em instituição de ensino; e (4) Outros - atuação em cargo sem relação 


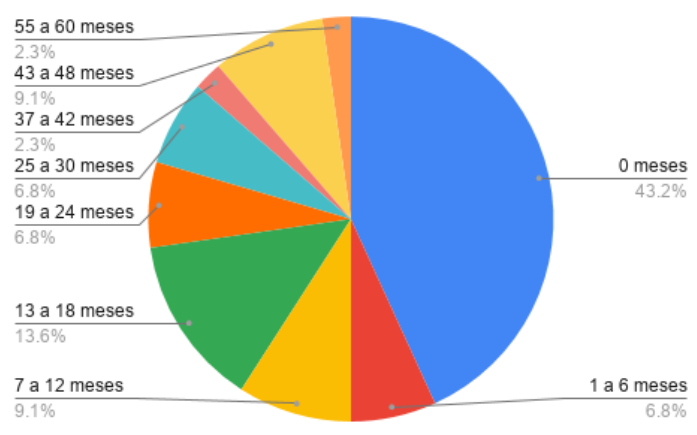

(a) $\mathrm{CC}$

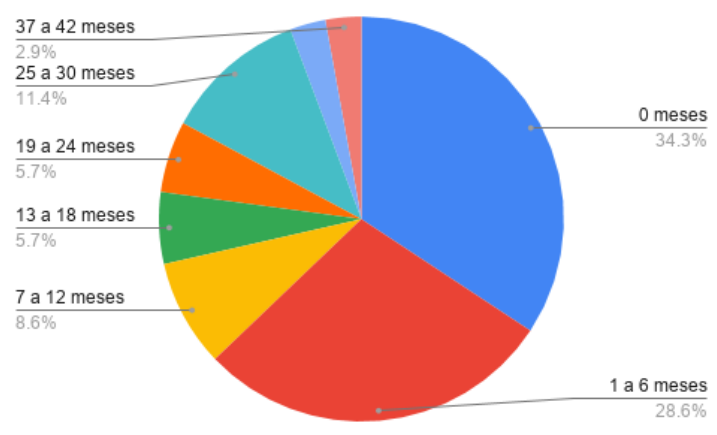

(b) ES

Figura 4. Tempo em meses para ingressar no mercado de trabalho

com área de formação.

A Figura 5 mostra a distribuição dos egressos na primeira e na última atuação. Pode ser observado que a distribuição dos egressos de ES não apresentou variação entre a primeira e a última atuação. A maioria dos egressos de ES $(65,7 \%)$ atuaram em instituições de TI e menos de 6,0\% não atuaram na área de formação. Já a distribuição dos egressos de CC apresentou diferença entre a primeira e a última atuação. Destacase que, na primeira atuação, quase $16,0 \%$ dos egressos de CC não atuaram na área de formação. Esse percentual reduziu para 6,5\% na última atuação. Adicionalmente, na última atuação, houve um aumento de egressos de CC em instituições de ensino.

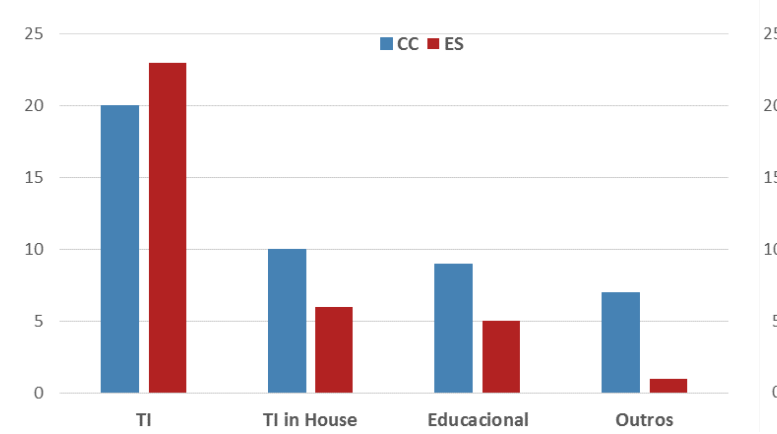

(a) Primeira atuação

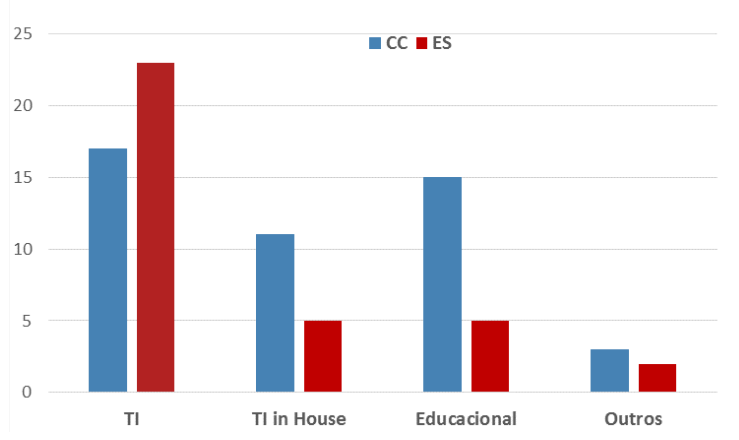

(b) Última atuação

Figura 5. Ramo das instituições na primeira e na última atuação

A Tabela 3 exibe a frequência de cargos ocupados na primeira e na última atuação. Os cargos da área de TI com frequência inferior a 3 foram agrupados em Outros na área de TI, enquanto os cargos não relacionados à área de formação foram agrupados em Outros. O cargo mais ocupado, independentemente do curso, é o de Programador de Sistemas de Informação. O cargo de Professor é mais ocupado por egressos de CC e o de Analista de Desenvolvimento de Sistemas por egressos de ES. Ainda, observa-se que os cargos de Administrador de Redes e Técnico em TI foram ocupados apenas por egressos de CC.

Em relação às remunerações, a Figura 6 apresenta a distribuição dos egressos por faixa salarial na primeira e na última atuação no mercado de trabalho. Na primeira 
IX Congresso Brasileiro de Informática na Educação (CBIE 2020)

Anais do XXXI Simpósio Brasileiro de Informática na Educação (SBIE 2020)

Tabela 3. Frequência dos cargos ocupados na primeira e na última atuação

\begin{tabular}{|c|c|c|c|c|c|c|c|c|}
\hline \multirow{2}{*}{ Cargo* } & \multicolumn{4}{|c|}{ Primeira } & \multicolumn{4}{|c|}{ Última } \\
\hline & \multicolumn{2}{|c|}{$\mathbf{C C}$} & \multicolumn{2}{|c|}{ ES } & \multicolumn{2}{|c|}{$\mathbf{C C}$} & \multicolumn{2}{|r|}{ ES } \\
\hline Administrador de Redes & 5 & $10,9 \%$ & 0 & $0,0 \%$ & 2 & $4,3 \%$ & 0 & $0,0 \%$ \\
\hline Analista de Desenvolvimento de Sistemas & 4 & $8,7 \%$ & 8 & $22,9 \%$ & 5 & $10,9 \%$ & 9 & $25,7 \%$ \\
\hline Analista de Suporte Computacional & 2 & $4,3 \%$ & 1 & $2,9 \%$ & 0 & $0,0 \%$ & 1 & $2,9 \%$ \\
\hline Gerente de Desenvolvimento de Sistemas & 3 & $6,5 \%$ & 4 & $11,4 \%$ & 3 & $6.5 \%$ & 5 & $14,3 \%$ \\
\hline Professor & 7 & $15,2 \%$ & 5 & $14,3 \%$ & 11 & $23,9 \%$ & 5 & $14,3 \%$ \\
\hline Programador de Sistemas de Informação & 12 & $26,1 \%$ & 12 & $34,3 \%$ & 11 & $23,9 \%$ & 11 & $31,4 \%$ \\
\hline Técnico de Apoio ao Usuário & 1 & $2,2 \%$ & 2 & $5,7 \%$ & 1 & $2,2 \%$ & 0 & $0,0 \%$ \\
\hline Técnico em TI & 1 & $2,2 \%$ & 0 & $0,0 \%$ & 4 & $8,7 \%$ & 0 & $0,0 \%$ \\
\hline Outros na área de TI & 5 & $10,9 \%$ & 1 & $2,9 \%$ & 5 & $10,9 \%$ & 2 & $5,7 \%$ \\
\hline Outros & 6 & $13,0 \%$ & 2 & $5,7 \%$ & 4 & $8,7 \%$ & 2 & $5,7 \%$ \\
\hline
\end{tabular}

atuação, 8 egressos de CC e 2 egressos de ES preferiram não informar a remuneração. Já na última atuação, 5 egressos de CC e 5 egressos de ES preferiram essa opção.

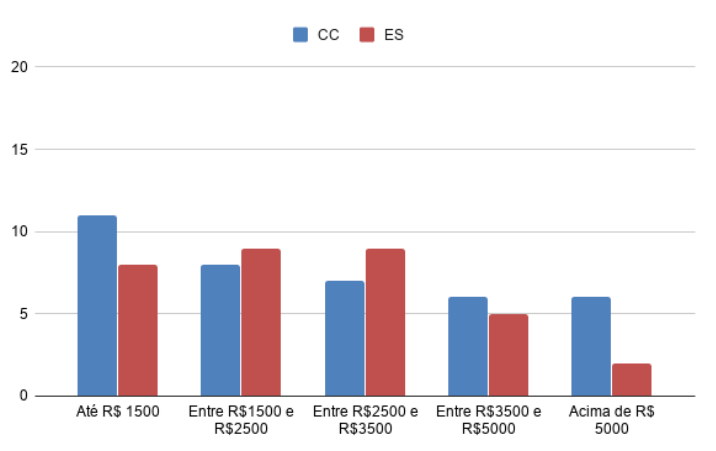

(a) Primeira atuação

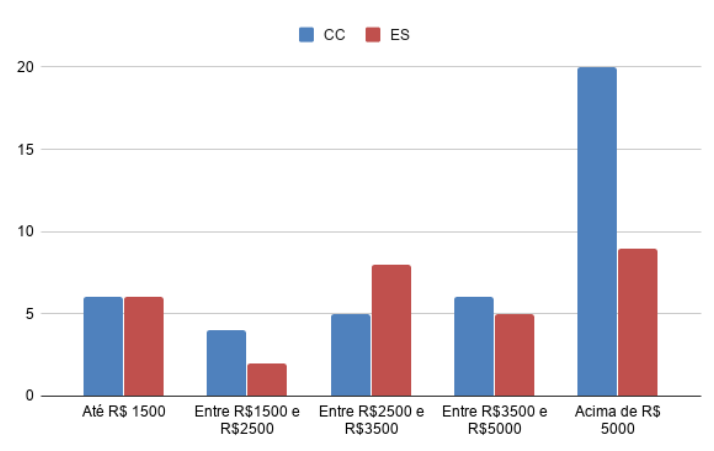

(b) Última atuação

\section{Figura 6. Faixa salarial na primeira e na última atuação}

Considerando os egressos que informaram a faixa salarial, na primeira atuação, $68,4 \%$ dos egressos de CC e 78,8\% dos egressos de ES receberam até R $\$ 3.500,00$, enquanto $15,8 \%$ dos egressos de CC e $6,1 \%$ dos egressos de ES receberam acima de R\$ 5.000,00. Atualmente, 36,6\% dos egressos de CC e 53,3\% dos egressos de ES recebem até $\mathrm{R} \$ 3.500,00$, enquanto 48,8\% dos egressos de $\mathrm{CC}$ e 30,0\% dos egressos de ES recebem acima de $\mathrm{R} \$ 5.000,00$.

\section{Discussão}

A Tabela 4 sintetiza os principais resultados, destacando as semelhanças e diferenças encontradas entre os perfis dos egressos de CC e ES. Observa-se que, em termos quantitativos, resultados com diferença de até $5,0 \%$ foram considerados similares.

$\mathrm{Na}$ dimensão pós-graduação, mais especificamente nos tipos especialização e mestrado, nota-se que os egressos dos dois cursos possuem comportamentos similares: poucos procuram por especialização ou MBA (inferior a 17\%) e mais da metade (55\% em CC e 57\% em ES) realizam mestrado. Especialmente, em relação ao mestrado, observase que as DCN mencionam a responsabilidade dos cientistas da computação em atuar 
IX Congresso Brasileiro de Informática na Educação (CBIE 2020)

Anais do XXXI Simpósio Brasileiro de Informática na Educação (SBIE 2020)

Tabela 4. Síntese das semelhanças (S) e diferenças (D) entre os perfis

\begin{tabular}{|c|c|c|c|}
\hline Critério & $\mathbf{C C}$ & ES & S/D \\
\hline Realizou especialização & $13,1 \%$ & $16,2 \%$ & $\mathrm{~S}$ \\
\hline Realizou mestrado & $59,0 \%$ & $56,8 \%$ & $\mathrm{~S}$ \\
\hline Realizou doutorado & $19,7 \%$ & $10,8 \%$ & $\mathrm{D}$ \\
\hline Áreas + pesquisadas mestrado & $\begin{array}{l}\text { SI }(25,0 \%), \text { CPD }(16,7 \%) \text {, } \\
\text { RC }(13,8 \%)\end{array}$ & $\begin{array}{l}\text { QS (14,3\%), DS (9,5\%), MS } \\
(9,5 \%)\end{array}$ & $\mathrm{D}$ \\
\hline Áreas + pesquisadas doutorado & SI $(33,3 \%)$, CPD $(33,3 \%)$ & $\begin{array}{l}\text { SI }(50,0 \%), \text { CPD }(25,0 \%) \text {, } \\
\text { GSI }(25,0 \%)\end{array}$ & $\mathrm{S}$ \\
\hline Experiência profissional & $75,4 \%$ & $94,6 \%$ & $\mathrm{D}$ \\
\hline Facilidade na inserção & $59,0 \%$ & $70,3 \%$ & $\mathrm{D}$ \\
\hline Ingresso em até 6 meses & $50,0 \%$ & $62,9 \%$ & $\mathrm{D}$ \\
\hline Primeira atuação na área & $84,8 \%$ & $97,1 \%$ & $\mathrm{D}$ \\
\hline Última atuação na área & $93,5 \%$ & $94,4 \%$ & $\mathrm{~S}$ \\
\hline Primeiros cargos + ocupados & $\begin{array}{l}\text { Programador de SI }(26,1 \%) \text {, } \\
\text { Professor }(15,2 \%) \text {, Outros } \\
(13,0 \%)\end{array}$ & $\begin{array}{l}\text { Programador de SI }(34,3 \%) \text {, } \\
\text { Analista de DS }(22,9 \%) \text {, Pro- } \\
\text { fessor }(14,3 \%)\end{array}$ & $\mathrm{D}$ \\
\hline Últimos cargos + ocupados & $\begin{array}{l}\text { Programador de SI }(23,9 \%) \text {, } \\
\text { Professor }(23,9 \%) \text {, Analista } \\
\text { de DS }(10,9 \%)\end{array}$ & $\begin{array}{l}\text { Programador de SI }(31,4 \%) \text {, } \\
\text { Analista de DS }(25,7 \%) \text {, Pro- } \\
\text { fessor }(14,3 \%)\end{array}$ & $\mathrm{D}$ \\
\hline Primeiro salário $>\mathrm{R} \$ 5.000,00$ & $15,8 \%$ & $6,1 \%$ & $\mathrm{D}$ \\
\hline Último salário $>\mathrm{R} \$ 5.000,00$ & $48,8 \%$ & $30,0 \%$ & $\mathrm{D}$ \\
\hline
\end{tabular}

no desenvolvimento científico e tecnológico da Computação (perfil específico - inciso I). Já para os engenheiros de software, o ensino e a pesquisa são mencionados como competência específica (inciso X). Alguns fatores podem estar contribuindo para que os egressos optem pelo mestrado: 1) influência do corpo docente, que na sua maioria possui formação em CC e atua nos dois cursos; 2) mercado de trabalho incipiente na região onde o curso é ofertado, que faz com que muitos egressos optem por fazer pós-graduação.

Quanto a área de pesquisa no mestrado, os egressos de cada curso tendem a realizar pesquisa na sua área de formação, o que caracteriza uma diferença no perfil. No entanto, observa-se que um percentual significativo de egressos de ES (38\%) pesquisam na área de CC. É possível que isso ocorra porque ainda existe um número menor de programas de pós-graduação em ES, mas também porque muitos egressos ao longo da graduação realizam iniciação científica com professores que pesquisam na área de CC.

Em relação ao doutorado, embora o número de respondentes que informaram ter feito ou estar fazendo seja pequeno (inferior a 20\%), a partir de uma análise mais detalhada verificou-se que 57\% dos egressos de CC que já concluíram o mestrado optaram pelo doutorado. Esse cenário novamente parece estar alinhado ao que as DCN instituem no perfil específico de CC (inciso I). Já mais da metade dos egressos de ES (56\%) que concluíram o mestrado foram para o mercado de trabalho, indicando um maior alinhamento com as DCN que abordam com bastante evidência aspectos de desenvolvimento de software tanto no perfil específico (incisos I a V) como nas competências do engenheiro de software (incisos I a XIV). Neste aspecto, portanto, há uma diferença no perfil.

Nota-se que existe uma semelhança na área de pesquisa escolhida pelos egressos de ambos os cursos no doutorado. A escolha pela área de Sistemas Inteligentes (SI), na qual aspectos de Inteligência Artificial e Aprendizado de Máquina são abordados, pode 
estar relacionada com o seu evidente crescimento, bem como a possibilidade de aplicação em problemas do domínio de ambos os cursos. Nas DCN não existe menção à criação de conhecimento cientifico em áreas específicas.

Ao analisar a dimensão atuação profissional, evidencia-se a diferença entre os perfis dos egressos. Isso também é observado nas DCN, que instituem para os egressos de CC competências e habilidades que abrangem sistemas de computação como um todo e para ES competências e habilidades mais relacionadas ao desenvolvimento de software, as quais possuem uma grande demanda no mercado de trabalho.

Destaca-se que em ambos os cursos a maioria dos egressos tem experiência no mercado de trabalho, porém nota-se um percentual maior entre os egressos de ES (94,6\%). Além disso, a inserção no mercado de trabalho foi considerada mais fácil por egressos de ES do que CC, o que pode estar associado aos seguintes fatores: (1) rápida colocação, visto que a maioria dos egressos de ES ingressou no mercado em até 6 meses; (2) realização de estágio obrigatório; e (3) adoção da metodologia ABP no currículo, que permite desenvolver ao longo do curso habilidades, como: comunicação, negociação e trabalho em equipe; que são necessárias para a atuação profissional.

Em relação aos cargos, embora a maioria dos cargos ocupados pelos egressos sejam os mesmos, o percentual de ocupação pelos egressos de CC e ES possui diferenças. Tanto na primeira como na última atuação, o cargo mais ocupado por ambos é o de Programador de Sistemas de Informação. Acredita-se que isso se deve ao fato deste cargo ser um dos mais ofertados, tornando-se uma porta de entrada para o mercado de trabalho. Além disso, destaca-se a alta ocupação no cargo de Analista de Desenvolvimento de Sistemas por egressos de ES, cujas habilidades e competências comumente requeridas estão presentes nas DCN do curso. Já em relação aos egressos de CC, a atuação como Professor aparece com um percentual considerável, nota-se, porém, que entre as habilidades e competências presentes nas DCN de CC não há menção a atividades de docência. Sobre as remunerações, os egressos de CC tendem a receber salários mais elevados em comparação com os egressos de ES, desde a primeira atuação. Em relação ao aumento da remuneração na última atuação, isso pode ser justificado devido aos egressos de CC possuírem, em média, mais tempo no mercado de trabalho e com isso tiveram mais oportunidades de evolução salarial. Adicionalmente, observa-se que houve um aumento na ocupação do cargo de professor por egressos de CC, o que também contribuiu.

\section{Considerações Finais}

Neste trabalho foram apresentados e discutidos dados que ajudam a entender o perfil dos egressos de dois cursos da área de Computação (CC e ES) a partir da sua realidade. Pesquisas como esta podem colaborar na adequação dos currículos de acordo com o perfil do egresso desejado. Isso se aplica principalmente nas instituições de ensino que oferecem os dois cursos e devem estabelecer com clareza o perfil do egresso, especialmente, para os docentes, que muitas vezes ministram disciplinas em ambos os cursos.

A partir da análise dos resultados obtidos, entende-se que, em relação à formação acadêmica, não é possível dizer se os perfis dos cursos são diferentes ou similares, visto que somente dois dos cinco critérios analisados apresentaram diferenças e que, ao contrário do que era esperado, um percentual expressivo de egressos de ES realizaram mestrado, o que não é mencionado no perfil específico de ES nas DCN mas encontra-se 
nas habilidades e competências do curso. Já em relação à atuação profissional, conclui-se que há uma diferença significativa no perfil dos egressos dos dois cursos, visto que oito dos nove critérios analisados apresentaram distinções, o que está em consonância com as habilidades e competências das DCN de cada curso.

As limitações deste estudo incluem: (1) instrumento com número extenso de questões, o que pode ter influenciado no número de respondentes e na qualidade das respostas; (2) 40,8\% dos respondentes com até três anos de graduados, o que limita algumas análises como a realização do doutorado e a remuneração; (3) as respostas refletem a realidade de uma instituição, impedindo que algumas conclusões sejam generalizadas.

Como trabalhos futuros citam-se: (1) prosseguir com o acompanhamento dos egressos a fim de confirmar ou refutar as conclusões deste estudo; (2) analisar o impacto das metodologias de aprendizagem utilizadas nos cursos em relação à atuação profissional; e (3) analisar a trajetória dos egressos em função do desempenho durante a graduação.

\section{Referências}

Brasscom (2017). Guia de Funções de Tecnologia da Informação e Comunicação no Brasil. Disponível em: https://brasscom.org.br/wp-content/uploads/2017/08/brasscomguia_de_funcoes_de_tic_2a_edicao-2017.pdf. Acesso em: 18 jul. 2020.

da Silva Figueiredo, K., de Azevedo, J. K. N., Azevedo, J. G., de Arruda dos Santos, K. A., de Souza Rosa Gomes, R., Ventura, T. M., and Maciel, C. (2018). Perfil dos Egressos e Egressas de Computação de Mato Grosso no Mercado de Trabalho. In Anais do IX Computer on the Beach, pages 209-306. Universidade do Vale do Itajaí.

Garcia, V., Santana, B., Gaiardo, G., Lucca, L., Cardoso, P., and Librelotto, G. (2018). Perfil dos Egressos do Curso de Ciência da Computação da Universidade Federal de Santa Maria (Extendido), pages 37-53.

Hazzan, O. (2007). The influence of software intangibility on computer science and software engineering education. SIGSOFT Softw. Eng. Notes, 32(3):7-8.

Meziane, F. and Vadera, S. (2004). A comparison of computer science and software engineering programmes in english universities. In 17th Conference on Software Engineering Education and Training, 2004. Proceedings., pages 65-70.

Ministério da Educação (2016). Resolução n ${ }^{0}$ 5, de 16 de novembro de 2016.

Parnas, D. L. (1999). Software engineering programs are not computer science programs. IEEE Software, 16(6):19-30.

Rasool, G. and Tahir, T. (2014). A comparison of software engineering and computer science undergraduate programs in pakistan. In 2014 12th International Conference on Frontiers of Information Technology, pages 97-102.

UNIPAMPA (2009). Universidade Federal do Pampa. Projeto Político-Pedagógico do Curso de Ciência da Computação. Alegrete, RS, 2009. Disponível em: http://dspace.unipampa.edu.br/handle/riu/97. Acesso em: 18 jul. 2020.

UNIPAMPA (2010). Universidade Federal do Pampa. Projeto Político-Pedagógico do Curso de Engenharia de Software. Alegrete, RS, 2010. Disponível em: http://dspace.unipampa.edu.br/handle/riu/100. Acesso em: 18 jul. 2020. 